Review Article

\title{
Use of Big Data Tools and Industrial Internet of Things: An Overview
}

\author{
Yingzi Wang $\mathbb{D}^{1},{ }^{1}$ Muhammad Nazir Jan, ${ }^{2}$ Sisi $\mathrm{Chu}^{3}$ and Yue $\mathrm{Zhu}^{3}$ \\ ${ }^{1}$ College of Intelligence and Computing, TianJin University, TianJin 300300, China \\ ${ }^{2}$ Department of Computer Science, University of Swabi, Swabi, Pakistan \\ ${ }^{3}$ Automotive Data of China Co.,Ltd., TianJin 300300, China \\ Correspondence should be addressed to Yingzi Wang; wangyingzi@catarc.ac.cn
}

Received 8 September 2020; Revised 26 September 2020; Accepted 3 October 2020; Published 21 October 2020

Academic Editor: Habib Ullah Khan

Copyright ( $\odot 2020$ Yingzi Wang et al. This is an open access article distributed under the Creative Commons Attribution License, which permits unrestricted use, distribution, and reproduction in any medium, provided the original work is properly cited.

Big data is ever playing an important role in the industry as well as many other organizations. With the passage of time, the volume of data is increasing. This increase will create huge bulk of data which needs proper tools and techniques to handle its management and organization. Different techniques and tools are being used to properly handle the management of data. A detailed report of these techniques and tools is needed which will help researchers to easily identify a tool for their data and take help to easily manage the data, organize the data, and extract meaningful information from it. The proposed study is an endeavour toward summarizing and identifying the tools and techniques for big data used in Industrial Internet of Things. This report will certainly help researchers and practitioners to easily use the tools and techniques for their need in an effective way.

\section{Introduction}

With the passage of time, the volume of data is increasing. In today's digital world, the information surges with the extensive use of the Internet and global communication systems. This increase will create huge bulk of data which needs proper tools and techniques to handle its management and organization. Big data is ever playing an important role in the industry as well as many other organizations. Huge bulk of data is produced from the healthcare information systems, electronic records, wearables, smart devices, handheld devices, and so on. The recent increase in medical big data and the development of computational techniques in the field of information technology enable researchers and practitioners to extract and visualize big data in a new spectrum of use.

The industry is leading toward the spreading out and developments of IIoT with the incorporation of emerging technologies and applications of IoT. The aim of the IIoT is to achieve high efficiency of operations for management of industrial assets and to increase the productivity of industries. More attention is given to the applications of IoT with its integration to industries. The applications of IoT are obvious in every field of life from industry to education, healthcare, and to other places. A number of studies are available related to the applications, uses, and different approaches to handle big data [1-8]. Different techniques and tools are being used for extracting important information from big data. The data are mostly unstructured which need proper structure, shape, and management through which the data can easily be accessed and processed. The role of visualization is to capture the important information from the data and to visualize it for the easiness of practitioners. Some of the programming tools which deal with big data are Informatica PowerCenter, Apache Hadoop, and Tableau, which analyze data extremely efficiently and enable the visualization of meaningful insights extracted from big data.

To facilitate the management of data for easy access and to operate, there should be a detailed report on the existing tools and techniques which can easily access, manage, operate, and execute useful information from the data for different purposes. Therefore, to facilitate this process, a detailed report of the existing literature is presented in this study. This detailed report will help researchers and scholars 
to devise new algorithms, techniques, and tools for the analysis and management of big data.

The organization of the paper is as follows. Section 2 shows the related work to big data tools and support of the industry. Section 3 presents the existing approaches to support big data in IIoT. Section 4 shows the support of IIoT regarding big data tools and techniques. The paper is concluded in Section 5.

\section{Big Data Tools and Support of the Industry}

With the advancements in Industrial Internet of Things (IIoT) sensing, communication, technology characterizations, and high throughput instrumentation, the level of data generation is expected to grow exponentially [9]. Lin et al. [10] presented an approach of integrating sensing data from diverse sources and equipment to apply on IIoT. The industrial Micro Control Unit is connected to interface with actuator, data sources, and equipment. The experimental results show that IIoT can reduce the problem of heterogeneous protocol and database manufacturing data transmission. This article demonstrates the complexity and unique nature of multimedia big data (MMBD) computing for Internet of Things (IoT) applications as well as builds up an inclusive taxonomy used for MMBD abstracted into a new process model reflecting MMBD over IoT. Many research challenges linked with $\mathrm{MMBD}$, for example, quality of service requirements, heterogeneity, reliability, accessibility, and scalability, are addressed by the process model. The process model is discussed through a case study [11]. In this work, architecture for flood forecasting and monitoring is proposed by means of convergence between HPC and big data. This architecture can analyze, store, and collect big data as well as help in the flood prediction result generation [12]. Mobile computing services can be used in IoT by using services of mobile phones, apps, or through M-Health care system [13]. Alexopoulos et al. [14] presented the IIoT architecture and its development details to support the industrial product service system life cycle.

In this article, a novel model is developed in the perspective of manufacturing progression that reviews the key big data analytics (BDA) capabilities. The findings are beneficial for the companies in order to understand big data potential implications as well as their analytics capabilities for their manufacturing processes and efficient BDA-enabler infrastructure design [15]. Boyes et al. [16] presented the concept of IIoT and the association to the ideas such as cyber physical systems and Industry 4.0. IoTrelated taxonomies were analyzed and an analysis framework was developed for IIoT that can be used to list and characterize the devices of IIoT when analyzing security vulnerability and threats. For the big data sentiment analysis (BDSA) and for best or optimal decision selection, a framework was proposed and also applied as a mathematical algorithm [17]. In this study, for big data and Cognitive Internet of Things (CIoT), a new architecture is proposed. The planned architecture helps the computing systems through combining data lake (DL) and warehouse (DWH), and for the collection of heterogeneous data, a tool is defined [18]. Urquhart and Mcauley [19] presented an approach for the risks of IIoT drawn both on the regulatory and technical perspectives. In this study, functional and structural properties of cloud manufacturing (CMfg) were analyzed, and a business intelligence architecture was proposed that plans to empower distributing pertinent KPIs identified with intrigued process data, with the helpful layer of dependability [20].

An overview of big data in smart manufacturing was directed, and an applied framework was proposed from the viewpoint of item life cycle. This framework permits examining key advantages and potential applications, and the debate of future research directions and current challenges gives essential insights for the industry and scholarly world [21]. This paper examines the current big data analytics (BDA) technologies, strategies, and algorithms that can prompt the improvement of insightful Industrial Internet of Things (IIoT) frameworks. We devise a scientific classification by characterizing and classifying the literature based on essential factors (for example, analytics types, industrial analytics applications, requirements, analytics techniques, analytics tools, and data sources). The case studies and frameworks of different endeavours were presented which have been profited by BDA [22]. This paper investigates how firms can capture an incentive from big data to improve green commitment by giving an applied model through an exhaustive and all-encompassing writing that relates big data sources to the reception of various green systems. The principle finding of the examination is that organizations that need to execute clean innovation strategy frequently allude to outside accomplice to build up the essential architecture expected to abuse enormous information potentialities [23]. Apart from these approaches, the big data and IoT have several other applications in diverse issues of the real world [24-28].

\section{Existing Approaches to Support Big Data in IIoT}

Humayun et al. [29] presented a comprehensive report of the evolution, prevention, and mitigation of ransomware in the context of IoT. For smart factories, construction path and reference architecture were proposed by examining IIoT technology as well as their application in assembling workshops. Joined with the examination of business as usual and requirements of the discrete assembling undertaking workshops, this paper structures the overall theoretical model architecture of the framework [30]. In this examination, a blockchain-dependent data sharing scheme was proposed that entirely considers efficiency as well as security of data sharing. In this plan, a Hyperledger Fabric and identity authentication-dependent secure data sharing structure was designed for the data sharing security. Additionally, a network recognition algorithm was proposed to partition the customers into various data sharing networks as per the comparability of mark data. The exploratory outcomes demonstrate that the proposed colloboration is successful for efficient and secure data sharing among various customers [31]. 
This paper discusses about the IoT data management concepts and current and survey solutions, talks about the most encouraging solutions, and recognizes important open exploration issues on the theme giving rules to assist further contributions [32]. In this article, for a scalable pipeline to distribute as well as process data as of blend of shop-floor sources, an architecture was proposed. The architecture was implemented in order to explore the feasibility of this methodology and bring together ad hoc power data and MTConnect-compliant machine to help analytics applications [33]. This work presents a procedure data examination stage which worked around the idea of Industry 4.0. The platform uses the big data software tools, ML algorithms, and state-of-the-art IIoT platforms. The results indicated that in situations where process information about the procedure within reach is restricted, information-driven delicate sensors are helpful instruments for predictive data investigation [34]. For industrial data processing, an Industrial Internet of Things cloud-fog hybrid network (ITCFN) framework was proposed. The results have shown that the proposed framework effectively reduces the processing delay of industrial data [35].

In this study, a systematic strategy was used to review the weaknesses as well as strengths of open-source technologies for stream processing and big data to set up its usage for Industry 4.0 use cases [36]. A framework was developed for the additive manufacturing enterprises by combining sustainable smart manufacturing technologies, additive manufacturing, and big data analytics. The proposed framework is beneficial for additive manufacturing industry leaders to take the right decision at the beginning stage of the product life cycle [37]. The big data characteristic of the testbed was studied by using an inhouse-developed IoT-enabled manufacturing testbed [38]. A distributed service-oriented architecture was provided for the solution of problem of product tracing [39]. The distributions of droplet size with high-velocity airblast atomization were examined [40]. In this article, an interactive data investigation framework was proposed, which poses a service-oriented perspective on the smart factory [23]. This article investigates the potential of artificial intelligence (AI) as well as machine learning (ML) to lever big data and Internet of Things (IoT) in smart cities in personalised service development. IoT smart city applications are suggested so as to benefit from this work [41]. Gierej [42] presented the idea of a business model for the companies implementing IIoT technologies. The approach is developed to help traditional companies in the transition of the digital market.

The proof procurement challenge is examined. A contextual investigation of a smart city venture with IoT administrations gathering big data which are put away in the cloud processing condition is presented. The strategies can be summed up to other big data in the cloud environment [43]. A fault prediction technique dependent on industrial big data is presented, which legitimately exhumes the connection between the data, for example, the status as well as sound data, and the equipment faults by machine learning techniques [44]. Distributed growing self-organizing map (DGSOM) and a novel distributed selfadaptive neural network algorithm were presented to tackle unsupervised machine learning need of big data [45]. Younan et al. [46] presented a study with a comprehensive review of the existing challenges in the literature and recommended technologies for enabling the analysis of data and search in the future IoT search engines. Two case studies are presented to show promising growth on smartness and intelligence of applications of IoT based on the integration of information and communication technologies. The applications of smart phones enable the patients to know about their diseases after the analysis in the field of gynaecology and paediatrics [47]. In this article, an architecture based on Internet of Things is proposed for big data that is used for diverse smart cities. The results demonstrated that this kind of method has the potential of the applicability to give beneficial services of smart cities, for example, detection of travel profiles in smart transport, comfort in smart buildings, and management of the energy consumption [48]. Jiang [49] presented an approach which studies the IoT developments and technologies related to cloud computing and smart cities and then focussed on the IoT technologies and cloud computing. Dachyar et al. [50] conducted an in-depth analysis of the 26420 papers published in the area of IoT. This article aims to adapt and detect concept drift dependent on cognitive learning principles. The approach executes to detect concept drift, determines concept drift type as well as in automated time windows [51]. Table 1 shows the existing approaches, methods, and tools to support big data.

\section{Support of IIoT regarding Big Data Tools and Techniques}

Several studies exist related to the applications of big data in IIoT. The study presented an enhanced platform of industrial big data for the reduction of time and data storage space of data processing [54]. The aim of the paper is to assess the impact of different serialization and compression methods on the platform of big data and then attempt to select the most suitable method for the platform of industry. The aim of the study is to propose a fabric which is a technique of blockchain-based data transmission for IIoT [56]. The approach uses secret sharing mechanism based on blockchain. The paper presented an approach of city geospatial dashboard for the collection, sharing, and visualization of the data collected from different sources like satellite data, IoT devices, and other big data [58]. The contribution of the paper is to present the concept of constructing community-based platform of cross IIoT service through utilizing the existing mobile and fixed facilities as wireless IoT gateway in a city which facilitates the easy implementation of IoT gateway at local service for bringing economical and social values [59]. The study focussed on the spatiotemporal modeling to organize the data in temporal, attributive, and spatial dimensions [60]. To manage the multisource manufacturing data, ontologybased big data integration mechanism is presented. The authors proposed an ADTT-advanced distributed tensor- 
TABLE 1: Existing approaches, methods, and tools to support big data.

\begin{tabular}{|c|c|c|}
\hline S.No & Reference & Title \\
\hline 1 & [9] & Big data analytics tool based on statistical process monitoring for smart manufacturing \\
\hline 2 & {$[11]$} & Multimedia big data computation and applications of IoT \\
\hline 3 & {$[12]$} & IoT, big data, and HPC-based smart flood management framework \\
\hline 4 & {$[15]$} & Big data analytics for manufacturing processes \\
\hline 5 & {$[17]$} & $\begin{array}{l}\text { An algorithmic implementation of entropic ternary reduct soft sentiment set using soft computing technique on big data } \\
\text { sentiment analysis for optimal selection of a decision based on real-time update in online reviews }\end{array}$ \\
\hline 6 & [18] & Architecture for Cognitive IoT and big data \\
\hline 7 & {$[20]$} & Challenges and opportunities for publishing IIoT data in manufacturing \\
\hline 8 & [21] & A comprehensive review of big data analytics throughout product life cycle to support sustainable smart manufacturing \\
\hline 9 & {$[22]$} & Role of big data analytics in IIoT \\
\hline 10 & [23] & Big data and natural environment \\
\hline 11 & [30] & Intelligent manufacturing production line data monitoring system for IIoT \\
\hline 12 & [31] & A secure and efficient data sharing scheme based on blockchain in IIoT \\
\hline 13 & {$[32]$} & Data management techniques for IoT \\
\hline 14 & [33] & Scalable data pipeline architecture to support the IIoT \\
\hline 15 & [34] & Industry 4.0 -based process data analytics platform \\
\hline 16 & [35] & Optimization of IIoT data processing latency \\
\hline 17 & [36] & Big data and stream processing platforms for Industry 4.0 requirements mapping for a predictive maintenance use case \\
\hline 18 & [37] & Framework of big data for sustainable and smart additive manufacturing \\
\hline 19 & [38] & Feature engineering in big data analytics for IoT-enabled smart manufacturing \\
\hline 20 & [39] & An architecture for aggregating information from distributed data nodes for IIoT \\
\hline 21 & {$[40]$} & Application of big data analysis technique on high-velocity airblast atomization \\
\hline 22 & [23] & Interactive data exploration as a service for the smart factory \\
\hline 23 & [41] & Smart city services using machine learning, IoT, and big data \\
\hline 24 & {$[43]$} & Digital forensics challenges to big data in the cloud \\
\hline 25 & {$[44]$} & On fault prediction based on industrial big data \\
\hline 26 & {$[45]$} & Apache spark-based distributed self-organizing map algorithm for sensor data analysis \\
\hline 27 & [48] & Techniques of big data to smart city deployments \\
\hline 28 & [51] & A cognitive data stream mining technique for context-aware IoT systems \\
\hline 29 & {$[52]$} & Implementation of the FSO2 \\
\hline 30 & {$[53]$} & $\begin{array}{l}\text { An intelligent outlier detection method with one class support tucker machine and genetic algorithm toward big sensor } \\
\text { data in IoT }\end{array}$ \\
\hline 31 & [54] & Big data-based improved data acquisition and storage system for designing industrial data platform \\
\hline 32 & [55] & Cybersecurity in an IIoT environment \\
\hline 33 & {$[56]$} & A secure fabric blockchain-based data transmission technique for IIoT \\
\hline 34 & [57] & Concept drift detection and adaption in big imbalance IIoT data using an ensemble learning method of offline classifiers \\
\hline 35 & [58] & City geospatial dashboard \\
\hline 36 & [59] & A community-based IoT service platform to locally disseminate socially valuable data \\
\hline 37 & {$[60]$} & The spatiotemporal modeling and integration of manufacturing big data in job shop \\
\hline 38 & [61] & A big data-enabled consolidated framework for energy efficient software defined data centers in IoT setups \\
\hline 39 & {$[62]$} & A parallel military dog-based algorithm for clustering big data in cognitive IIoT \\
\hline 40 & {$[63]$} & Big data cleaning based on mobile edge computing in industrial sensor cloud \\
\hline 41 & {$[64]$} & A highly efficient distributed tensor-train decomposition method for IIoT big data \\
\hline 42 & [65] & Big data-driven edge-cloud collaboration architecture for cloud manufacturing \\
\hline
\end{tabular}

train-decomposition approach along with a computational method for the IIoT big data processing [64]. The existing literature was searched in order to identify the associated materials related to the proposed study. For this purpose, the popular libraries such as ACM, IEEE, ScienceDirect, and Springer were considered to show the related materials. The reason behind these libraries was that these libraries publish quality materials which are peer reviewed. Figure 1 shows the number of papers published in the given years in the library of ScienceDirect. The last five years were considered as the latest research published in these recent years.

Figure 2 shows the article type along with the number of publications in the given library.
Figure 3 shows publication titles and percentage of publications.

Figure 4 shows the articles types and number of publications in the library IEEE.

Figure 5 shows the publication topics and percentages of number of publications.

Figure 6 shows the media format and number of publications in the ACM library.

Figure 7 shows the publication types and number of papers published in the given library.

Figure 8 shows the number of publications in the given years.

Figure 9 shows the article types and percentages of publication in the Springer library. 
No. of papers

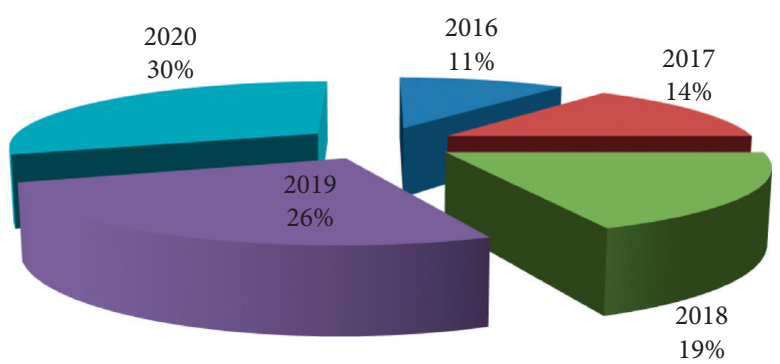

Figure 1: Number of papers in the given year for ScienceDirect.

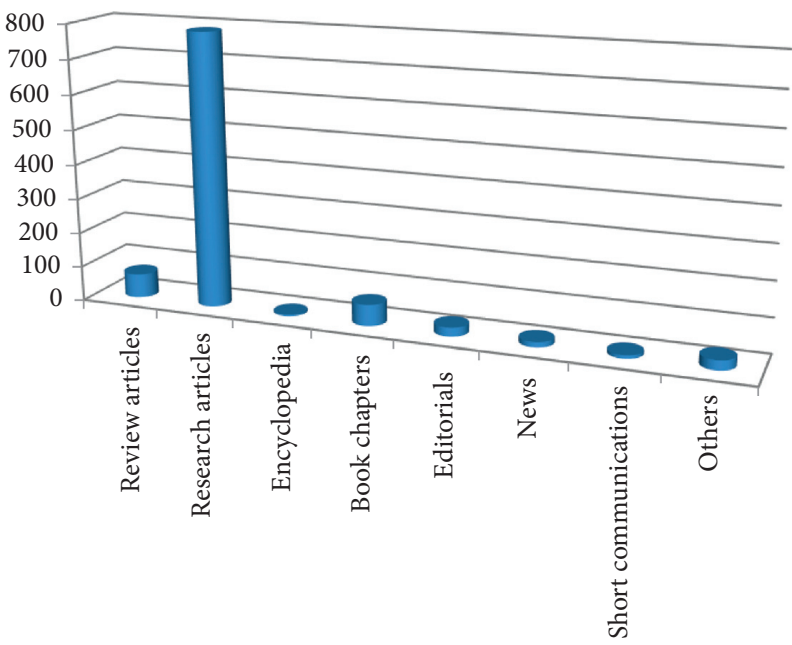

FIgURE 2: Article type and number of publications.

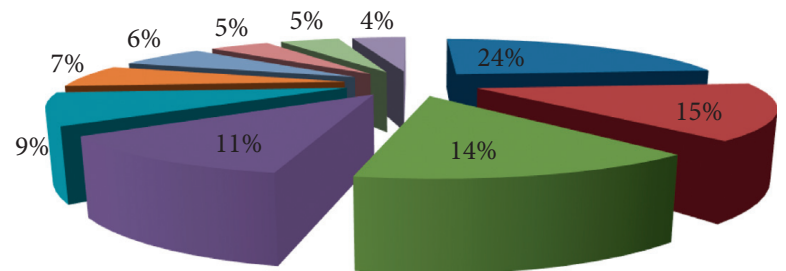

- Procedia manufacturing

- IFAC-papersonline

- Future generation computer systems

- Journal of network and computer applications

- Computer networks

- Procedia CIRP

- Procedia computer science

- Computer communications

- Computers in industry

- Computers \& industrial engineering

Figure 3: Publication titles and number of publications. 


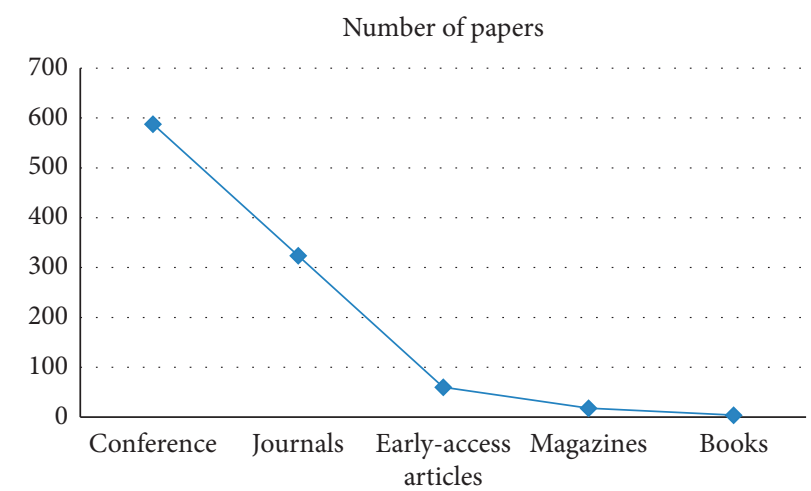

FIGURE 4: Articles type and number of publications.

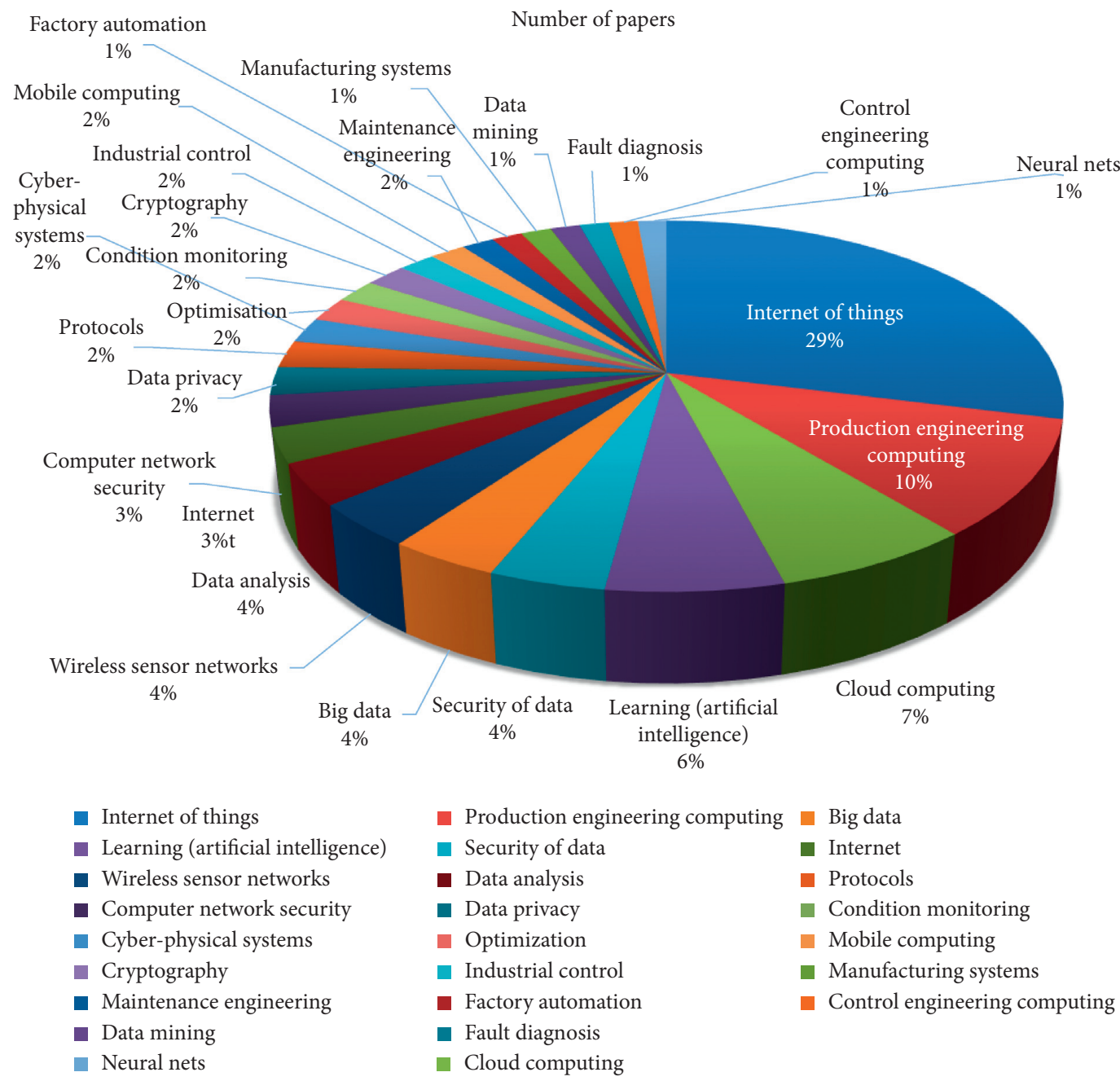

FIgURE 5: Publication topics and percentage of publications. 


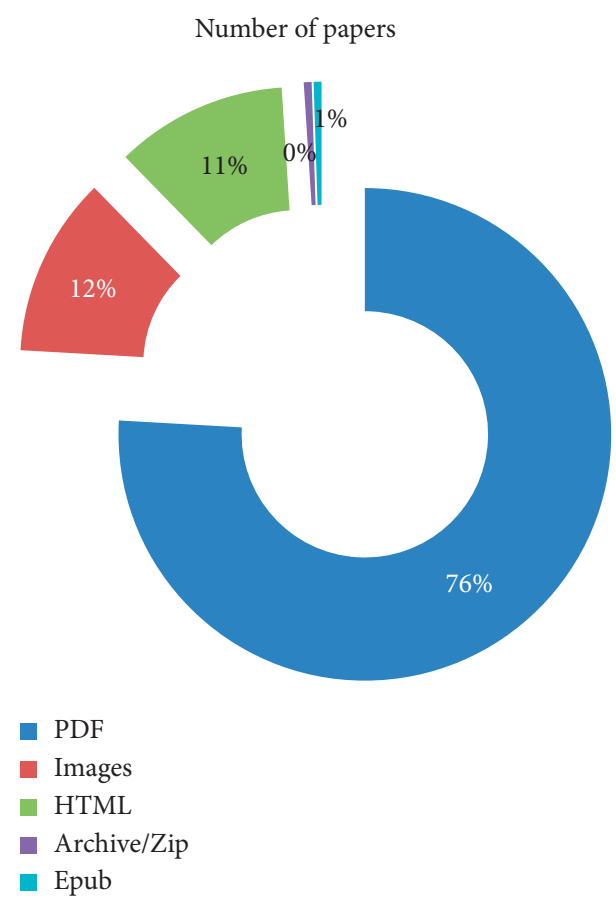

FIgURE 6: Media format and number of publications.

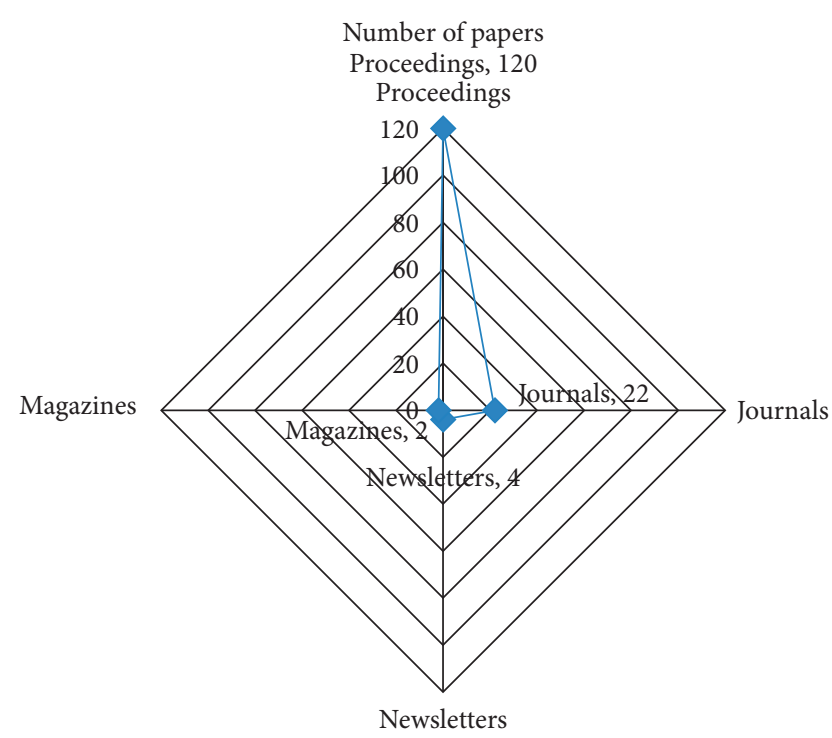

Figure 7: Publication types and number of papers.

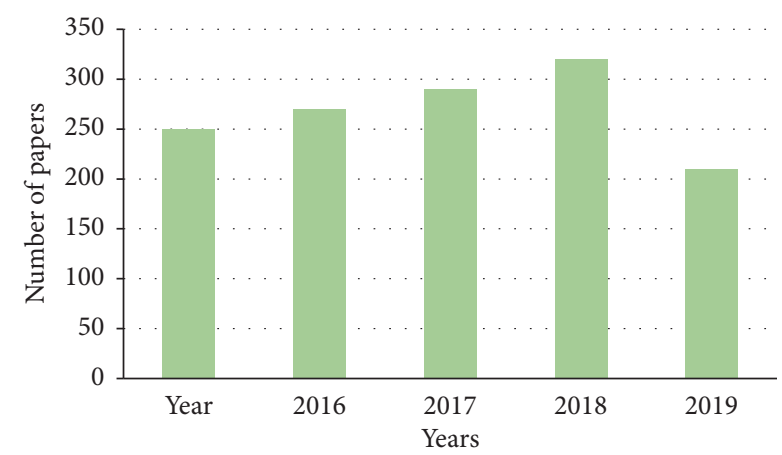

FIgURE 8: Number of papers in the given years.

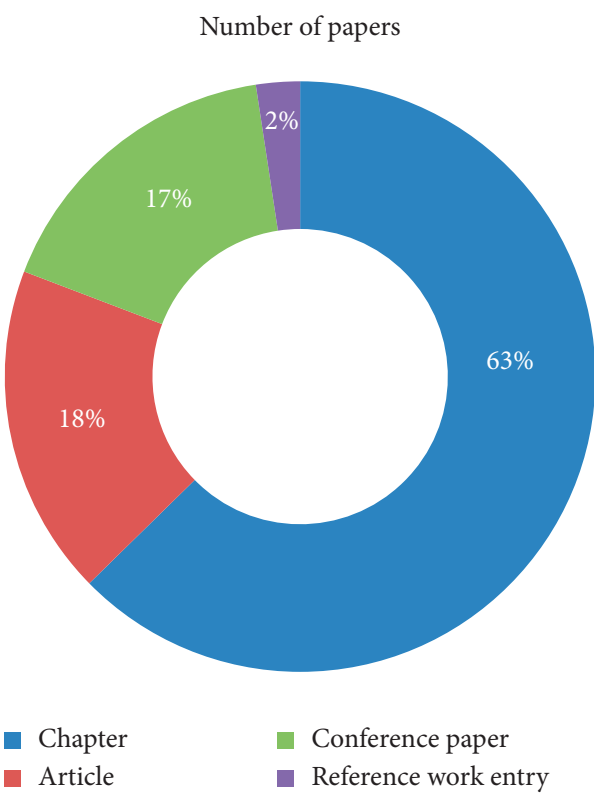

Figure 9: Content types and percentage of publications.

\section{Conclusion}

With the passage of time, the volume of data is increasing. This increase will create huge bulk of data which needs proper tools and techniques to handle its management and organization. Big data is ever playing an important role in the industry as well as many other organizations. Huge bulk of data is produced from the healthcare information systems, electronic records, wearables, smart devices, handheld devices, and so on. The recent increase in medical big data and the development of computational techniques in the field of information technology enable researchers and practitioners to extract and visualize big data in a new spectrum of use. Different techniques and tools are being used to properly handle the management of data. A detailed report of these techniques and tools is needed which will help researchers to easily identify a tool for their data and take help to easily manage the data, organize the data, and extract meaningful information from it. The proposed study is an endeavour toward summarizing and identifing the tools and techniques for big data used in IIoT. This report will help researchers and practitioners to easily use the tools and techniques for their need in an effective way and will devise new solutions for the industry of big data.

\section{Data Availability}

No data were used to support this study.

\section{Conflicts of Interest}

The authors declare that they have no conflicts of interest regarding this paper.

\section{Acknowledgments}

This study was sponsored in part by the Intelligent Manufacturing Project of Tianjin (20193155). 


\section{References}

[1] E. Yadegaridehkordi, M. Nilashi, L. Shuib et al., "The impact of big data on firm performance in hotel industry," Electronic Commerce Research and Applications, vol. 40, p. 100921, 2020.

[2] S. Asadi, R. H. Abdullah, M. Safaei, and S. Nazir, "An integrated sem-neural network approach for predicting determinants of wearable healthcare devices adoption," Mobile Information Systems, vol. 2019, Article ID 8026042, 9 pages, 2019.

[3] S. Nazir, S. Khan, H. U. Khan et al., "A comprehensive analysis of healthcare big data management, analytics and scientific programming," IEEE Access, vol. 8, pp. 95714-95733, 2020.

[4] S. Nazir, M. Nawaz, A. Adnan, S. Shahzad, and S. Asadi, "Big data features, applications, and analytics in cardiology-A systematic literature review," IEEE Access, vol. 7, no. 1, pp. 143742-143771, 2019.

[5] S. Nazir, M. Nawaz Khan, S. Anwar et al., "Big data visualization in cardiology-A systematic review and future directions," IEEE Access, vol. 7, no. 1, pp. 115945-115958, 2019.

[6] A. U. Haq, "Intelligent machine learning approach for effective recognition of diabetes in the E-healthcare using clinical data," Sensors, vol. 20, 2020.

[7] S. Nazir, S. Ali, M. Yang, and Q. Xu, "Deep learning algorithms and multi-criteria decision making used in big data- a systematic literature review," Security and Communication Networks, vol. 2020, Article ID 2836064, 19 pages, 2020.

[8] S. Nazir, A Comprehensive Analysis of Healthcare Big Data Management, Analytics and Scientific Programming, IEEE Access, Piscataway, NJ, USA, 2020.

[9] Q. P. He and J. Wang, "Statistical process monitoring as a big data analytics tool for smart manufacturing," Journal of Process Control, vol. 67, pp. 35-43, 2018.

[10] Y. J. Lin, C.-B. Lan, and C.-Y. Huang, "A realization of cyberphysical manufacturing Control system through industrial internet of things," Procedia Manufacturing, vol. 39, pp. 287-293, 2019.

[11] A. Kumari, S. Tanwar, S. Tyagi, N. Kumar, M. Maasberg, and K.-K. R. Choo, "Multimedia big data computing and internet of things applications: a taxonomy and process model," Journal of Network and Computer Applications, vol. 124, pp. 169-195, 2018.

[12] S. K. Sood, R. Sandhu, K. Singla, and V. Chang, "IoT, big data and HPC based smart flood management framework," Sustainable Computing: Informatics and Systems, vol. 20, pp. 102-117, 2018.

[13] S. H. Almotiri, M. A. Khan, and M. A. Alghamdi, "Mobile health (m-health) system in the context of IoT," in Proceedings of the 2016 IEEE 4th International Conference on Future Internet of Things and Cloud Workshops, IEEE, Vienna, Austria, pp. 39-42, August 2016.

[14] K. Alexopoulos, S. Koukas, N. Boli, and D. Mourtzis, "Architecture and development of an industrial internet of things framework for realizing services in industrial product service systems," Procedia CIRP, vol. 72, pp. 880-885, 2018.

[15] A. Belhadi, K. Zkik, A. Cherrafi, S. R. M. Yusof, and S. El fezazi, "Understanding big data analytics for manufacturing processes: insights from literature review and multiple case studies," Computers \& Industrial Engineering, vol. 137, Article ID 106099, 2019.

[16] H. Boyes, B. Hallaq, J. Cunningham, and T. Watson, "The industrial internet of things (IIoT): an analysis framework," Computers in Industry, vol. 101, pp. 1-12, 2018.
[17] A. Dwivedi and R. P. Pant, "An algorithmic implementation of entropic ternary reduct soft sentiment set (ETRSSS) using soft computing technique on big data sentiment analysis (BDSA) for optimal selection of a decision based on real-time update in online reviews," Journal of King Saud UniversityComputer and Information Sciences, 2019.

[18] M. S. Hadj Sassi, F. G. Jedidi, and L. C. Fourati, "A new architecture for cognitive internet of things and big data," Procedia Computer Science, vol. 159, pp. 534-543, 2019.

[19] L. Urquhart and D. McAuley, "Avoiding the internet of insecure industrial things," Computer Law \& Security Review, vol. 34, no. 3, pp. 450-466, 2018.

[20] J. Ordieres-Meré, J. Villalba-Díez, and X. Zheng, "Challenges and opportunities for publishing IIoT data in manufacturing as a service business," Procedia Manufacturing, vol. 39, pp. 185-193, 2019.

[21] S. Ren, Y. Zhang, Y. Liu, T. Sakao, D. Huisingh, and C. M. V. B. Almeida, "A comprehensive review of big data analytics throughout product life cycle to support sustainable smart manufacturing: a framework, challenges and future research directions," Journal of Cleaner Production, vol. 210, pp. 1343-1365, 2019.

[22] M. H. ur Rehman, I. Yaqoob, K. Salah, M. Imran, P. P. Jayaraman, and C. Perera, "The role of big data analytics in industrial internet of things," Future Generation Computer Systems, vol. 99, pp. 247-259, 2019.

[23] F. Calza, A. Parmentola, and I. Tutore, "Big data and natural environment. How does different data support different green strategies?" Sustainable Futures, vol. 2, Article ID 100029, 2020.

[24] V. F. Brock and H. U. Khan, "Are enterprises ready for big data analytics? A survey-based approach," International Journal of Business Information Systems, vol. 25, no. 2, pp. 256-277, 2017.

[25] V. Brock and H. U. Khan, "Big data analytics: does organizational factor matters impact technology acceptance?” vol. 4, no. 1, p. 21, 2017.

[26] B. Liao, Y. Ali, S. Nazir, L. He, and H. U. Khan, "Security analysis of IoT devices by using mobile computing: a systematic literature review," IEEE Access, vol. 8, pp. 120331120350, 2020.

[27] M. Madhuri, A. Q. Gill, and H. U. Khan, "IoT-enabled smart child safety digital system architecture," in Proceedings of the 2020 IEEE 14th International Conference on Semantic Computing, IEEE, San Diego, CA, USA, pp. 166-169, 2020.

[28] A. Q. Gill, G. Beydoun, M. Niazi, and H. U. Khan, "Adaptive architecture and principles for securing the IoT systems," in Proceedings of the International Conference on Innovative Mobile and Internet Services in Ubiquitous Computing, pp. 173-182, Springer, Lodz, Poland, 2020.

[29] M. Humayun, N. Z. Jhanjhi, A. Alsayat, and V. Ponnusamy, "Internet of things and ransomware: evolution, mitigation and prevention," Egyptian Informatics Journal, 2020.

[30] W. Chen, "Intelligent manufacturing production line data monitoring system for industrial internet of things," Computer Communications, vol. 151, pp. 31-41, 2020.

[31] J. Chi, Y. Li, J. Huang et al., "A secure and efficient data sharing scheme based on blockchain in industrial internet of things," Journal of Network and Computer Applications, vol. 167, Article ID 102710, 2020.

[32] B. Di Ã"ne, J. J. P. C. Rodrigues, O. Diallo, E. L. H. M. Ndoye, and V. V. Korotaev, "Data management techniques for internet of things," Mechanical Systems and Signal Processing, vol. 138, Article ID 106564, 2020. 
[33] M. Helu, T. Sprock, D. Hartenstine, R. Venketesh, and W. Sobel, "Scalable data pipeline architecture to support the industrial internet of things," CIRP Annals, vol. 69, no. 1, pp. 385-388, 2020.

[34] J. C. Kabugo, S.-L. Jämsä-Jounela, R. Schiemann, and C. Binder, "Industry 4.0 based process data analytics platform: a waste-to-energy plant case study," International Journal of Electrical Power \& Energy Systems, vol. 115, Article ID 105508, 2020.

[35] W. Liu, G. Huang, A. Zheng, and J. Liu, "Research on the optimization of IIoT data processing latency," Computer Communications, vol. 151, pp. 290-298, 2020.

[36] R. Sahal, J. G. Breslin, and M. I. Ali, "Big data and stream processing platforms for Industry 4.0 requirements mapping for a predictive maintenance use case," Journal of Manufacturing Systems, vol. 54, pp. 138-151, 2020.

[37] A. Majeed, Y. Zhang, S. Ren et al., "A big data-driven framework for sustainable and smart additive manufacturing," Robotics and Computer-Integrated Manufacturing, vol. 67, Article ID 102026, 2021.

[38] D. Shah, J. Wang, and Q. P. He, "Feature engineering in big data analytics for IoT-enabled smart manufacturing - comparison between deep learning and statistical learning," Computers \& Chemical Engineering, vol. 141, Article ID 106970, 2020.

[39] T. Zhu, S. Dhelim, Z. Zhou, S. Yang, and H. Ning, "An architecture for aggregating information from distributed data nodes for industrial internet of things," Computers \& Electrical Engineering, vol. 58, pp. 337-349, 2017.

[40] A. Urbán, A. Groniewsky, M. Malý, V. Józsa, and J. Jedelský, "Application of big data analysis technique on high-velocity airblast atomization: searching for optimum probability density function," Fuel, vol. 273, Article ID 117792, 2020.

[41] J. Chin, V. Callaghan, and I. Lam, "Understanding and personalising smart city services using machine learning, the Internet-of-Things and Big Data," in Proceedings of the 2017 IEEE 26th International Symposium on Industrial Electronics (ISIE), pp. 2050-2055, Edinburgh, Scotland, June 2017.

[42] S. Gierej, "The framework of business model in the context of industrial internet of things," Procedia Engineering, vol. 182, pp. 206-212, 2017.

[43] X. Feng and Y. Zhao, "Digital forensics challenges to big data in the cloud," in Proceedings of the 2017 IEEE International Conference on Internet of Things (iThings) and IEEE Green Computing and Communications (GreenCom) and IEEE Cyber, Physical and Social Computing (CPSCom) and IEEE Smart Data (SmartData), pp. 858-862, Exeter, UK, June 2017.

[44] Q. Han, H. Li, W. Dong, Y. Luo, and Y. Xia, "On fault prediction based on industrial big data," in Proceedings of the 2017 36th Chinese Control Conference (CCC), pp. 1012710131, Dalian, China, July 2017.

[45] M. Jayaratne, D. Alahakoon, D. D. Silva, and X. Yu, "Apache spark based distributed self-organizing map algorithm for sensor data analysis," in Proceedings of the IECON 2017-43rd Annual Conference of the IEEE Industrial Electronics Society, pp. 8343-8349, Beijing, China, November 2017.

[46] M. Younan, E. H. Houssein, M. Elhoseny, and A. A. Ali, "Challenges and recommended technologies for the industrial internet of things: a comprehensive review," Measurement, vol. 151, p. 107198, 2020.

[47] Y. Karaca, M. Moonis, Y.-D. Zhang, and C. Gezgez, "Mobile cloud computing based stroke healthcare system," International Journal of Information Management, vol. 45, pp. 250$261,2019$.
[48] M. V. Moreno, F. Terroso-Saenz, A. Gonzalez-Vidal et al., "Applicability of big data techniques to smart cities deployments," IEEE Transactions on Industrial Informatics, vol. 13, no. 2, pp. 800-809, 2017.

[49] D. Jiang, "The construction of smart city information system based on the Internet of Things and cloud computing," Computer Communications, vol. 150, pp. 158-166, 2020.

[50] M. Dachyar, T. Y. M. Zagloel, and L. R. Saragih, "Knowledge growth and development: internet of things (IoT) research, 2006â€“2018," Heliyon, vol. 5, no. 8, Article ID e02264, 2019.

[51] D. Nallaperuma, D. D. Silva, D. Alahakoon, and X. Yu, "A cognitive data stream mining technique for context-aware IoT systems," in Proceedings of the IECON 2017-43rd Annual Conference of the IEEE Industrial Electronics Society, pp. 4777-4782, Beijing, China, November 2017.

[52] A. Bamrungwong, "Implementation of the FSO2 life extension program by using big data and IIoT," in Proceedings of the 2019 Petroleum and Chemical Industry Conference Europe (PCIC EUROPE), pp. 1-8, Paris, France, May 2019.

[53] X. Deng, P. Jiang, X. Peng, and C. Mi, “An intelligent outlier detection method with one class support tucker machine and genetic algorithm toward big sensor data in internet of things," IEEE Transactions on Industrial Electronics, vol. 66, no. 6, pp. 4672-4683, 2019.

[54] D. Geng, C. Zhang, C. Xia, X. Xia, Q. Liu, and X. Fu, "Big databased improved data acquisition and storage system for designing industrial data platform," IEEE Access, vol. 7, pp. 44574-44582, 2019.

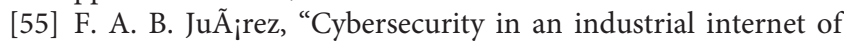
things environment (IIoT) challenges for standards systems and evaluation models," in Proceedings of the 2019 8th International Conference On Software Process Improvement, vol. 23, pp. 1-6, Leon, Mexico, October 2019.

[56] W. Liang, M. Tang, J. Long, X. Peng, J. Xu, and K. C. Li, “A secure FaBric blockchain-based data transmission technique for industrial internet-of-things," IEEE Transactions on Industrial Informatics, vol. 15, no. 6, pp. 3582-3592, 2019.

[57] C.-C. Lin, D.-J. Deng, C.-H. Kuo, and L. Chen, "Concept drift detection and adaption in big imbalance industrial IoT data using an ensemble learning method of offline classifiers," IEEE Access, vol. 7, pp. 56198-56207, 2019.

[58] K. K. Lwin, Y. Sekimoto, W. Takeuchi, and K. Zettsu, "City geospatial dashboard: IoT and big data analytics for geospatial solutions provider in disaster management," in Proceedings of the 2019 International Conference on Information and Communication Technologies for Disaster Management (ICT-DM), pp. 1-4, December 2019.

[59] Y. Shoji, K. Nakauchi, W. Liu, Y. Watanabe, K. Maruyama, and K. Okamoto, "A community-based IoT service platform to locally disseminate socially-valuable data :best effort local data sharing network with no conscious effort?" in Proceedings of the 2019 IEEE 5th World Forum on Internet of Things (WF-IoT), pp. 724-728, April 2019.

[60] W. Fang, Y. Guo, W. Liao, S. Huang, C. Yang, and K. Cui, "The spatio-temporal modeling and integration of manufacturing big data in job shop: an ontology-based approach," in IEEE 7th International Conference Oon Industrial Engineering Aand Applications (ICIEA), 16-21 April 2020 2020, pp. 394-398, 2020.

[61] K. Kaur, S. Garg, G. Kaddoum, E. Bou-Harb, and K.-K. R. Choo, "A bBig dData-eEnabled cConsolidated fFramework for eEnergy eEfficient sSoftware dDefined dData cCenters in IoT sSetups," IEEE Transactions on Industrial Informatics, vol. 16, no. 4, pp. 2687-2697, 2020. 
[62] A. K. Tripathi, K. Sharma, M. Bala, A. Kumar, V. G. Menon, and A. K. Bashir, "A parallel military dog based algorithm for clustering big data in cognitive industrial internet of things," IEEE Transactions on Industrial Informatics, p. 1, 2020.

[63] T. Wang, H. Ke, X. Zheng, K. Wang, A. K. Sangaiah, and A. Liu, "Big data cleaning based on mobile edge computing in industrial sensor-cloud," IEEE Transactions on Industrial Informatics, vol. 16, no. 2, pp. 1321-1329, 2020.

[64] X. Wang, L. T. Yang, L. Song, H. Wang, L. Ren, and J. Deen, "A tensor-based multi-attributes visual feature recognition method for industrial intelligence," IEEE Transactions on Industrial Informatics, p. 1, 2020.

[65] C. Yang, S. Lan, L. Wang, W. Shen, and G. G. Q. Huang, "Big data driven edge-cloud collaboration architecture for cloud manufacturing: a software defined perspective," IEEE Access, vol. 8, pp. 45938-45950, 2020. 